Received: 23 November 2017

Accepted: 10 October 2018

Published online: 26 October 2018
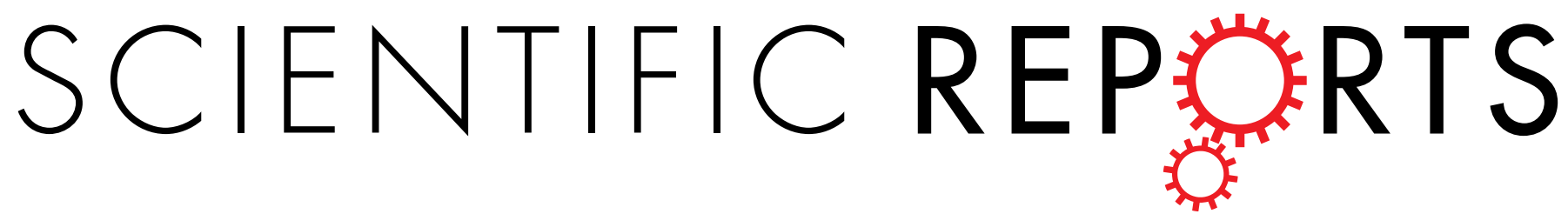

\section{OPEN Investigating the $\mathrm{Ca}^{2+}$-dependent and $\mathrm{Ca}^{2+}$-independent mechanisms for mammalian cone light adaptation}

Frans Vinberg $\mathbb{1}^{1,2}$ \& Vladimir J. Kefalov ${ }^{1}$

Vision is mediated by two types of photoreceptors: rods, enabling vision in dim light; and cones, which function in bright light. Despite many similarities in the components of their respective phototransduction cascades, rods and cones have distinct sensitivity, response kinetics, and adaptation capacity. Cones are less sensitive and have faster responses than rods. In addition, cones can function over a wide range of light conditions whereas rods saturate in moderately bright light. Calcium plays an important role in regulating phototransduction and light adaptation of rods and cones. Notably, the two dominant $\mathrm{Ca}^{2+}$-feedbacks in rods and cones are driven by the identical calcium-binding proteins: guanylyl cyclase activating proteins 1 and 2 (GCAPs), which upregulate the production of cGMP; and recoverin, which regulates the inactivation of visual pigment. Thus, the mechanisms producing the difference in adaptation capacity between rods and cones have remained poorly understood. Using GCAPs/recoverin-deficient mice, we show that mammalian cones possess another $\mathrm{Ca}^{2+}$-dependent mechanism promoting light adaptation. Surprisingly, we also find that, unlike in mouse rods, a unique $\mathrm{Ca}^{2+}$-independent mechanism contributes to cone light adaptation. Our findings point to two novel adaptation mechanisms in mouse cones that likely contribute to the great adaptation capacity of cones over rods.

Our daytime vision is mediated by cone photoreceptors, which can adapt quickly and over a wide range of ambient light levels. In contrast, rod photoreceptors, which mediate our dim light vision, adapt slower and saturate under bright light. However, the molecular underpinnings explaining the faster and more efficient capability of cones to light adapt, i.e. to regulate their sensitivity in response to increments and decrements of background light, are still poorly understood.

Absorption of a photon by visual pigment molecule triggers a $\mathrm{G}$ protein signaling cascade involving identical or homologous rod and cone proteins $s^{1,2}$. Briefly, a single photoactivated rod or cone pigment can activate several cell-specific heterotrimeric $\mathrm{G}$ proteins, transducins ${ }^{3-5}$. In turn, each of these transducins disinhibits a $\mathrm{rod} / \mathrm{cone}$-specific effector enzyme phosphodiesterase, $\mathrm{PDE} 6^{6,7}$. The resulting upregulated hydrolysis of cGMP by PDE6 leads to a lower cGMP concentration in the outer segments of photoreceptors, followed by closure of cGMP-gated (CNG) channels in their plasma membrane ${ }^{8}$, reduced influx of $\mathrm{Na}^{+}$and $\mathrm{Ca}^{2+}$, and ultimately cell hyperpolarization ${ }^{9,10}$. Continuous photoreceptor function requires the inactivation of the visual pigments, transducins and PDE6, and the upregulation of cGMP synthesis by guanylate cyclases (GC) to restore and maintain cGMP concentration ${ }^{11,12}$. The concerted activation and inactivation of these transduction components upon light stimulation is modulated by their properties and expression levels, and produces a light response with distinct

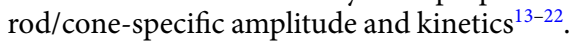

When background light levels change, photoreceptors adjust their sensitivity allowing vision even under rapidly changing ambient illumination. Part of this change in sensitivity is driven by the modulation of cGMP turno$\mathrm{ver}^{23}$. However, the dominant mechanism for modulating photoreceptor sensitivity in background light (referred to below as light adaptation) is thought to be driven by $\mathrm{Ca}^{2+}$-dependent feedback on the phototransduction cascade triggered by the decrease in outer segment $\mathrm{Ca}^{2+}$ concentration upon light stimulation ${ }^{24-27}$. This feedback

${ }^{1}$ Ophthalmology and Visual Sciences, Washington University School of Medicine, St. Louis, Missouri, USA. ${ }^{2}$ Present address: John A. Moran Eye Center, University of Utah, Salt Lake City, Utah, USA. Correspondence and requests for materials should be addressed to F.V. (email: frans.vinberg@hsc.utah.edu) 
is mediated by several $\mathrm{Ca}^{2+}$-binding proteins, including 1) Guanylate Cyclase Activating proteins (GCAP1 and GCAP2), which activate guanylyl cyclase and thus accelerate cGMP synthesis in low $\left.\mathrm{Ca}^{2+28,29}, 2\right)$ recoverin $(\mathrm{Rv})$, which dissociates from rhodopsin kinase (GRK1) in low $\mathrm{Ca}^{2+}$ allowing GRK1 to accelerate visual pigment inactivation in both rods and cones ${ }^{30-34}$, and, in the case of amphibian photoreceptors. 3) calmodulin and/or CNG modulin, which modulate the gating of CNG channels ${ }^{35-37}$. Notably, rods and cones share the same GCAPs and recoverin isoforms, leaving the question of the mechanisms that produce the difference in their light adaptation still open.

It has been demonstrated that light adaptation in amphibian rods and cones is mediated by $\mathrm{Ca}^{2+26,38}$. A recent study showed that the same is likely also true for mammalian rods $^{39}$ but whether mammalian cone light adaptation is mediated exclusively by $\mathrm{Ca}^{2+}$-dependent mechanisms is not known. Here we combined electrophysiology, pharmacology, and genetic approaches to dissect the contribution of $\mathrm{Ca}^{2+}$-dependent and $\mathrm{Ca}^{2+}$-independent mechanisms to the light adaptation capacity of mammalian cones in the absence of the known $\mathrm{Ca}^{2+}$ feedbacks mediated by GCAPs and recoverin.

\section{Methods}

Ethical approval. All experimental protocols were in accordance with the Guide for the Care and Use of Laboratory Animals and were approved by the institutional Animal Studies Committee at Washington University.

Animals. Mice were housed in the University's animal facilities under 12/12 hour light/dark cycle and had free access to water and regular rodent chow. The GCAPs $s^{-1-28}$ and $R v^{-1-40}$ mice were originally obtained from Dr. Jeannie Chen (University of Southern California) but were backcrossed for several generations to the Gnat $1^{-1-}$ background ${ }^{41}$ to allow for cone-specific recordings. We crossed these GCAPs ${ }^{-1-} \mathrm{Gnat1}^{-1-}$ and $\mathrm{Rv}^{-1-} \mathrm{Gnat1}^{-1-}$ to produce GCAPs ${ }^{-1-} \mathrm{Rv}^{-1-} \mathrm{Gnat1^{-l- }}$ mice. We then compared the functional properties of $\mathrm{G} n a t 1^{-1-}$ control cones and $\mathrm{GCAPs}^{-1-} \mathrm{Rv}^{-1-} \mathrm{Gnat1}^{-1-}$ cones to evaluate the functional contribution of residual $\mathrm{Ca}^{2+}$-dependent and any possible $\mathrm{Ca}^{2+}$-independent regulation of cone phototransduction. All tested mice were between 2-3 months of age. Mice were genotyped from tail samples by Transnetyx Inc. and were also tested to be free of $R d 8$ mutation $^{42}$.

Ex vivo Electroretinogram (ERG) Experiments. Transretinal ERG responses to flashes and steps of cyan LED light (505 nm Luxeon Rebel LED SR-01-E0070) from isolated mouse retinas were recorded as described previously ${ }^{43}$. Briefly, the retinas were mounted on a specimen holder where they were perfused $2 \mathrm{~mL} / \mathrm{min}$ with Locke's solution heated to $37^{\circ} \mathrm{C}$. The perfusion solution contained (in $\mathrm{mM}$ ): $\mathrm{NaCl}, 112 ; \mathrm{KCl}, 3.6 ; \mathrm{MgCl}_{2}, 2.4$; $\mathrm{CaCl}_{2}, 1.2$; HEPES, 10; $\mathrm{NaHCO}_{3}, 20$; $\mathrm{Na}_{2}$-succinate, 3; Na-glutamate, 0.5; glucose, 10. The solution was equilibrated with $95 \% \mathrm{O}_{2} / 5 \% \mathrm{CO}_{2}$ at $37^{\circ} \mathrm{C}$. In addition, $2 \mathrm{mM} \mathrm{L}$-Aspartate, $40 \mu \mathrm{M}$ DL-AP4 (Tocris Biosciences) and $100 \mu \mathrm{M} \mathrm{BaCl}_{2}$ were added to the medium to isolate the photoreceptor component of the ERG signal. Low $\mathrm{Ca}^{2+}$ solution was prepared by adding $0.4 \mathrm{mM}$ EGTA and substituting the $1.2 \mathrm{mM} \mathrm{CaCl}$ with only $0.1 \mathrm{mM} \mathrm{CaCl}_{2}$

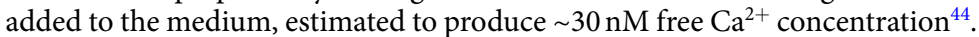

Signals were amplified initially by a differential amplifier (DP-311, Warner Instruments) and then amplified further and low-pass filtered at $300 \mathrm{~Hz}$ (8-pole Bessel, Krohn-Hite Corporation, model 3382) and sampled at $10 \mathrm{kHz}$ with $0.03 \mu \mathrm{V}$ resolution by a digitizer (1440 A Digidata, Molecular Devices) and pCLAMP 10 software (Molecular Devices). Light stimulation was provided by a custom-build LED system via optical cable (Newport, 77536) and the optics of an inverted microscope that produced homogenous light over the effective measurement area of $\varnothing 0.5 \mathrm{~mm}$ at the central retina. Light intensity and the length of light flashes $(1 \mathrm{~ms})$ and background light steps were controlled by an LED driver (Thorlabs, LDC210C) and neutral density filters. The total light power of the LED stimuli ( $\lambda_{\max }$ at $505 \mathrm{~nm}$; Rebel star, SR-01-E0070) was measured by calibrated optometer (UDT Instruments, Model 211) near the plane of the retina. The intensity was then calculated based on the light spot area at the plane of the retina $(\varnothing 2.35 \mathrm{~mm})$ and converted to a number of $505 \mathrm{~nm}$ photons $\mu \mathrm{m}^{-2} \mathrm{~s}^{-1}$.

Analysis. Origin 9.0.0 software (64-bit, SR2, OriginLab) was used for data analysis and figure preparation. A Naka-Rushton function was fitted to the response amplitude ( $r$ ) from Gnat1 ${ }^{-1-}$ control and $G C A P s^{-l-} \mathrm{Rv}^{-1-}$ Gnat $^{-1-}$ mouse cones:

$$
\frac{r}{r_{\max }}=\frac{I_{F}}{I_{1 / 2}+I_{F}},
$$

where $r_{\max }$ is the maximal amplitude of a saturated cone response, $I_{F}$ is the intensity of the light flash (in photons $\mu \mathrm{m}^{-2}$ ), and $I_{1 / 2}$ is the light intensity producing a half-maximal photoresponse.

A modified Weber-Fechner function was fitted to the light adaptation data:

$$
\frac{S_{F}}{S_{F, D}}=\frac{I_{0}^{n}}{I_{0}^{n}+I^{n}},
$$

where $S_{F}$ is the sensitivity of cones defined as the amplitude of a response to dim flash divided by the flash strength (in $505 \mathrm{~nm}$ photons $\mu \mathrm{m}^{-2}$ ), $S_{F, D}$ is the sensitivity in darkness defined as the amplitude of a response to dim flash divided by the flash strength with no background light present, $n$ is a slope factor, $I$ is the background light intensity (in 505 photons $\mu \mathrm{m}^{-2} \mathrm{~s}^{-1}$ ) and $I_{0}$ is the background light intensity at which the sensitivity $\mathrm{S}_{\mathrm{F}}$ drops to $50 \%$ of that in darkness. In all cases, response amplitude was measured at its peak.

The decline in sensitivity as a function background light intensity in the absence of light adaptation mechanisms was calculated by using two functions. Firstly, the exponential saturation function 

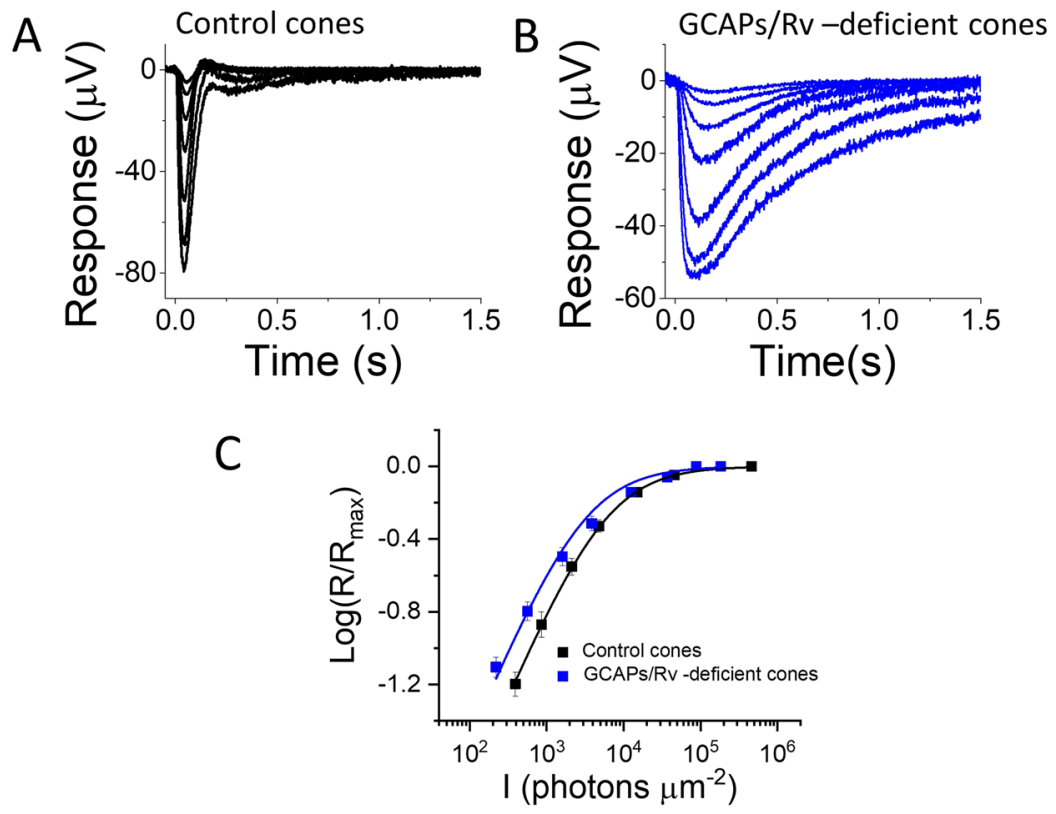

Figure 1. GCAPs/recoverin-deficient cones are more sensitive and have slower photoresponse kinetics. Responses of control (A) and GCAPs/recoverin-deficient (B) cones to flashes of $505 \mathrm{~nm}$ light from 400 to 460,000 and 220 to 180,000 photons $\mu \mathrm{m}^{-2}$ in control Gnat $1^{-I-}$ and $G C A P s^{-1-} \mathrm{Rv}^{-I-}$ Gnat $1^{-1-}$ mice, respectively. (C) Response amplitudes (mean \pm SEM) plotted as a function of flash intensity (in photons $\mu \mathrm{m}^{-2}$ ) for control Gnat $1^{-1-}$ (black squares, $\mathrm{n}=4$ mice) and GCAPs ${ }^{-1-} \mathrm{Rv}^{-1-}$ Gnat $1^{-1-}$ (blue squares, $\mathrm{n}=4$ mice) mice. The smooth lines plot Eq. (1) with $I_{1 / 2}=5,600$ photons $\mu \mathrm{m}^{-2}$ (black) and 3,000 photons $\mu \mathrm{m}^{-2}$ (blue) for control and GCAPs/recoverin-deficient cones, respectively.

$$
\frac{s_{F}}{s_{F, D}}=e^{-\frac{s_{F, D} T_{i} I}{r_{\max }}},
$$

where $\mathrm{T}_{\mathrm{i}}$ is the integration time of a dim flash response defined as the area between the trace and time-axis along the baseline of the response divided by the response peak amplitude and $r_{\max }$ is the maximal response amplitude of a saturated cone response. Alternatively, a function

$$
\frac{s_{F}}{s_{F, D}}=\frac{1}{\left(1+\frac{s_{F, D} T_{i} I}{3 r_{\max }}\right)^{4}}
$$

that has been derived by removing all the feedbacks from a phototransduction model was used ${ }^{45}$.

\section{Results}

Cones can light adapt in the absence of GCAPs and recoverin. The role of GCAP1, GCAP2 and recoverin $(\mathrm{Rv})$ in mouse rod and cone phototransduction and light adaptation has been well characterized $^{28,31,32,39,46-49}$. Here, we bred $G C A P s^{-/-}$(lacking both isoforms 1 and 2) and $R v^{-1-}$ mice to produce $G C A P s^{-1-}$ $R v^{-l-}$ double knockout mice. The rods and cones in these mice lack the $\mathrm{Ca}^{2+}$ feedbacks to modulate cGMP synthesis (via GCAP1/2) and active visual pigment lifetime (via recoverin) that are known to contribute to the rod and cone phototransduction termination and light adaptation ${ }^{28,31,32,46}$. To investigate how the simultaneous deletion of GCAPs and recoverin affects the phototransduction in mouse cones, we performed ex vivo ERG recordings from dark-adapted isolated retinas (see Methods, Fig. 1). To facilitate assessment of cone physiology, all of the mice were on Gnat $1^{-1-}$ background to remove the light responses originating from their rod photoreceptors $^{41}$. We compared the responses from control Gnat ${ }^{-1-}$ cones with the responses from $\mathrm{GCAPs}^{-1-} \mathrm{Rv}^{-1-}$ Gnat $1^{-1-}$ cones. The calcium feedback deficiency in $\mathrm{GCAPs}^{-1-} \mathrm{Rv}^{-1-} \mathrm{Gnat}^{-1-}$ cones resulted in slower shut-off of their photoresponses, leading to larger response integration time (Fig. 1A,B, and Table 1; see also ${ }^{46}$ ). The larger integration time also appeared to increase the sensitivity of $\mathrm{GCAPs}^{-1-} \mathrm{Rv}^{-1-} \mathrm{Gnat1}^{-1-}$ cones, as demonstrated by an apparent shift of their response amplitude data to dimmer light (Fig. 1C). As a result, the averaged cone light flash intensity required to elicit $50 \%$ of the maximal response $\left(I_{1 / 2}\right)$ was reduced by the deletion of GCAPs and recoverin (though the difference was not statistically significant, see Table 1). These results are consistent with previous rod studies showing that $\mathrm{GCAPs}^{-1-} \mathrm{Rv}^{-1-}$ rods are more sensitive to light and have slower response kinetics as compared to wild type $\operatorname{rods}^{28,40}$.

A recent study showed that GCAPs- and Rv-deficient mouse rods can still adapt to light ${ }^{39}$. However, the ability of cones lacking GCAPs and recoverin to modulate their phototransduction cascade has not been investigated. To address this question, we first recorded light responses of cones in isolated retinas to steps of light by using ex vivo 


\begin{tabular}{|c|c|c|c|c|c|c|}
\hline & $r_{\max }(\mu \mathrm{V})$ & $I_{1 / 2}\left(\right.$ phot. $\left.\mu \mathrm{m}^{-2}\right)$ & $t_{p}(\mathrm{~ms})$ & $T_{i}(\mathrm{~ms})$ & $I_{0}$ (phot. $\mu \mathrm{m}^{-2} \mathrm{~s}^{-1}$ ) & $n$ \\
\hline Control Gnat $1^{-1-}$ & $56 \pm 7$ & $5,500 \pm 700$ & $56 \pm 2$ & $71 \pm 5$ & $48,800 \pm 11,000$ & $1.0 \pm 0.1$ \\
\hline $\mathrm{GCAPs}^{-1-} \mathrm{Rv}^{-1-}$ Gnat1 $^{-1-}\left(\right.$ normal Ca $\left.{ }^{2+}\right)$ & $50 \pm 10$ & $3,800 \pm 400$ & $142 \pm 12^{*}$ & $240 \pm 40^{*}$ & $12,100 \pm 2,400$ & $1.5 \pm 0.1^{*}$ \\
\hline $\mathrm{GCAPs}^{-1-} \mathrm{Rv}^{-1}$ Gnat1 $^{-1-},\left(\right.$ low $\left.\mathrm{Ca}^{2+}\right)$ & $72 \pm 9^{\dagger}$ & $5,400 \pm 1,100^{\dagger}$ & $139 \pm 10$ & $420 \pm 30^{\dagger}$ & $42,900 \pm 6,400^{\dagger \dagger}$ & $2.0 \pm 0.2^{\dagger \dagger}$ \\
\hline
\end{tabular}

Table 1. Parameters of photoresponses from control Gnat $1^{-/-}$and from GCAPs ${ }^{-1-} \mathrm{Rv}^{-/-} \mathrm{Gnat1}^{-/-}$mouse cones in normal and low $\mathrm{Ca}^{2+} . r_{\max }$, saturated photoresponse amplitude; $I_{1 / 2}$, light flash intensity producing a half-maximal light response (see Eq. 1 ); $t_{p}$, time-to-peak of a dim flash response; $T_{i}$, integration time of a $\operatorname{dim}$ flash response defined as the integrated area between the response and baseline divided by the response amplitude; $I_{0}$, background light intensity reducing the sensitivity to $50 \%$ of the dark-adapted sensitivity; $n$, slope of the light adaptation curve (see Eq. 2). ${ }^{*} \mathrm{p}<0.05$ (paired t-test between control $\mathrm{Gnat}^{-1-}$ and GCAPs ${ }^{-1-}$ $\mathrm{Rv}^{-1-} \mathrm{Gnat1}^{-1-}$ data in normal Ca ${ }^{2+}$ ); ${ }^{\dagger} \mathrm{p}<0.05 ;{ }^{\dagger \dagger} \mathrm{p}<0.01$ (paired t-test between normal and low $\mathrm{Ca}^{2+}$ data of $\mathrm{GCAPs}^{-1-} \mathrm{Rv}^{-1-} \mathrm{Gnat1}^{-1-}$ mice). Control Gnat1 ${ }^{-l-}$ data (mean $\pm \mathrm{SEM}$ ) is from 4 mice, and GCAPs${ }^{-1-} \mathrm{Rv}^{-1-}$ $\mathrm{Gnat}^{-1-}$ data (mean $\left.\pm \mathrm{SEM}\right)$ is from 8 mice.
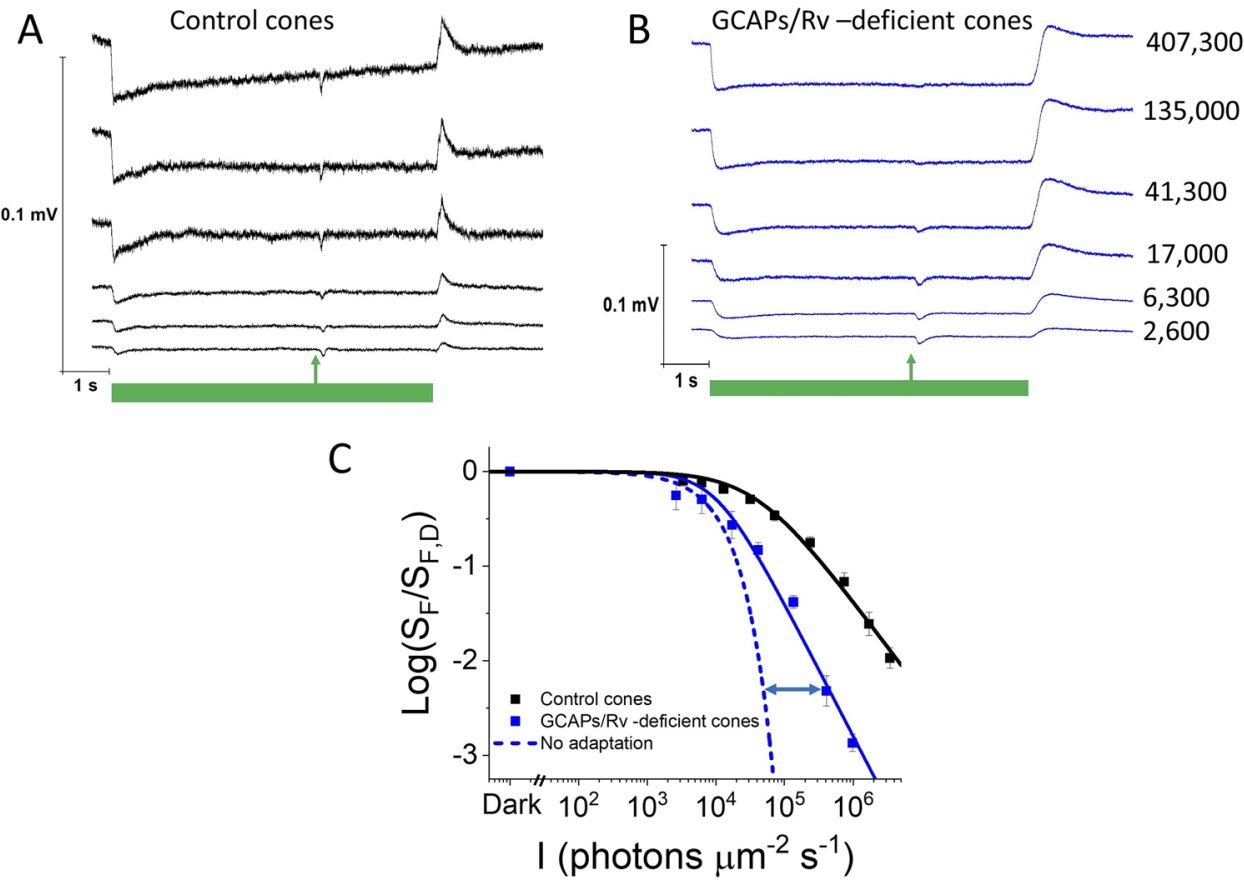

Figure 2. GCAPs/recoverin-deficient cones can adapt to background light. Responses of control (A) and GCAPs/recoverin-deficient (B) cones to steps of $505 \mathrm{~nm}$ light (indicated by green bars) from 2,620 up to 407,300 photons $\mu^{-2} \mathrm{~s}^{-1}$ (numbers on the right indicate the background light intensity, identical for A and B). A flash of light was delivered at $4.5 \mathrm{~s}$ after the step onset (arrow) to probe the sensitivity of cones $\left(S_{F}\right)$ during different backgrounds. (C) Normalized sensitivity $\left(S_{F} / S_{F D}\right.$, where $S_{F D}$ is the sensitivity in darkness, (mean \pm SEM) plotted as a function of background light intensity in photons $\mu \mathrm{m}^{-2} \mathrm{~s}^{-1}$ for control cones (black squares, $\mathrm{n}=4$ mice) and GCAPs/recoverin-deficient cones (blue squares, $\mathrm{n}=3$ mice). The smooth traces plot Eq. (2) with $I_{0}=39,600 \mu \mathrm{m}^{-2} \mathrm{~s}^{-1}$ and $n=1.0$ for control cones (black), and with $I_{0}=10,200 \mu \mathrm{m}^{-2} \mathrm{~s}^{-1}$ and $n=1.4$ for GCAPs/recoverin-deficient cones (blue). The blue dashed trace plots Eq. (3) calculated from the data measured from dark-adapted GCAPs/recoverin-deficient cones.

ERGs. In control Gnat $1^{-1-}$ cones, the initial hyperpolarization after the step onset was followed by partial recovery demonstrating the modulation of CNG channel current during steady background light (Fig. 2A). Exposure of cones lacking GCAPs and recoverin to identical steps of light produced larger responses as compared to those of control cones (Fig. 2A,B; note the different scale of the two y-axes). For example, the mean amplitude of step responses at steady state just before the test flash was flash was $2.6 \pm 1 \mu \mathrm{V}$ in control and $17 \pm 1 \mu \mathrm{V}$ at $\sim 41,000$ photons $\mu \mathrm{m}^{-2} \mathrm{~s}^{-1}$ background. This difference was highly significant $(\mathrm{n}=3, \mathrm{p}<0.0005)$. Interestingly, despite lacking the two major components of their calcium feedback, GCAPs ${ }^{-1-} \mathrm{Rv}^{-1-} \mathrm{Gnat1}^{-1-}$ cones also showed a prominent recovery after the initial hyperpolarization following the onset of light step. Thus, even in the absence of both GCAPs and recoverin, mouse cones were able to regulate their CNG channel current and light-adapt during steady background light (Fig. 2B). To assess the light adaptation capacity of $G C A P s^{-1-} R v^{-1-} G n a t 1^{-1-}$ cones, we probed their sensitivity in background lights of varying intensity by delivering a test flash $4.5 \mathrm{~s}$ after the onset of the background. As expected, the sensitivity of control Gnat $1^{-1-}$ cones declined according to Weber-Fechner 
A

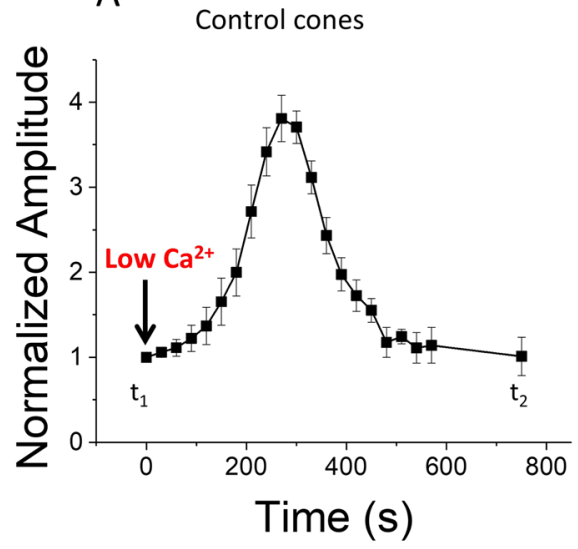

B

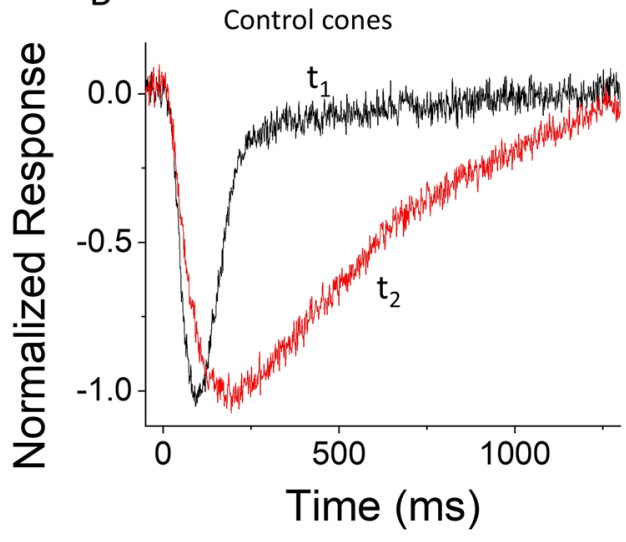

Figure 3. Low $\mathrm{Ca}^{2+}$ exposure causes large transient increase of $r_{\text {max }}$ and deceleration of flash response kinetics in control mouse cones. (A) Normalized maximal cone response amplitudes $\left(r_{\max }\right.$, mean $\pm \mathrm{SEM}, \mathrm{n}=4$ mice $)$ to a saturating bright test flash plotted as a function of time after exposing the retina to low $\mathrm{Ca}^{2+}$ medium. Amplitudes have been normalized to $r_{\max }$ just before the low $\mathrm{Ca}^{2+}$ exposure. (B) Averaged normalized responses (mean, $\mathrm{n}=4$ mice) of control cones to a dim test flash producing a response with amplitude $<20 \%$ of $r_{\text {max }}$ just before the low $\mathrm{Ca}^{2+}$ exposure (black) and about 10 min after the switch to low $\mathrm{Ca}^{2+}$ solution (red).

law (Fig. 2C, black, Table 1). In contrast, the sensitivity decline was steeper (i.e. $\mathrm{n}>1$ in Eq. 2, see Table 1) and appeared to be shifted to dimmer background lights in GCAPs ${ }^{-l-} R v^{-l-}$ Gnat $1^{-l-}$ cones (Fig. 2C, blue) than in controls (though, the change of $\mathrm{I}_{0}$ was not statistically significant, see Table 1 ). These results demonstrate that, as has been shown previously, GCAPs and recoverin are important for mouse cone light adaptation ${ }^{32,46}$. However, comparison of light adaptation in $G C A P s^{-1-} \mathrm{Rv}^{-1-} \mathrm{Gnat}^{-1-}$ cones to the expected decline of sensitivity in the absence of any adaptation mechanisms (Fig. 2C, blue dashed line) revealed that substantial light adaptation remains even in cones lacking both GCAPs and recoverin. This was confirmed by pair-wise comparison of the experimental data to the model data from six GCAPs ${ }^{-1-} \mathrm{Rv}^{-1-} \mathrm{Gnat}^{-1-}$ mice at six different background light intensities ranging from 2,600 to 236,000 photons $\mu \mathrm{m}^{-2} \mathrm{~s}^{-1}$. This comparison demonstrated a significant difference between measured and calculated (Eq. 3) sensitivity above $\sim 30,000$ photons $\mu \mathrm{m}^{-2} \mathrm{~s}^{-1}(\mathrm{p}<0.01$, paired Student t-test). The mechanisms for this GCAPs/Rv-independent light adaptation in mouse cones are currently not known. Here we investigated if the residual light adaptation capacity of GCAPs/Rv-deficient cones is mediated by $\mathrm{Ca}^{2+}$-dependent and/or $\mathrm{Ca}^{2+}$-independent pathway(s).

Modulation of CNG channel current and light response kinetics in cones by lowered Ca2+. The contribution of $\mathrm{Ca}^{2+}$-dependent mechanisms to the light adaptation of amphibian photoreceptors has been studied by several methods. Those methods include clamping $\mathrm{Ca}^{2+}$ concentration of a single photoreceptor to its dark-adapted or light-adapted level. This can be achieved for a brief time by removing $\mathrm{Na}^{+}$and $\mathrm{Ca}^{2+}$ from the extracellular solution in darkness or during steady background light, or by manipulating $\mathrm{Ca}^{2+}$ levels in truncated photoreceptor outer segments that can be dialyzed with GTP or cGMP to study cGMP synthesis and hydrolysis, respectively ${ }^{2638,50-55}$. These methods require rapid changes of extracellular environment of single cells or truncated outer segment compartments of photoreceptors, manipulations that are not well tolerated by fragile and small mouse rod or cone outer segments. Here, we adopted a different approach to force the cone phototransduction to its maximally light adapted state. We achieved that by lowering the extracellular $\mathrm{Ca}^{2+}$ concentration to drive intracellular $\mathrm{Ca}^{2+}$ level below that attained in bright light, thus fully engaging the $\mathrm{Ca}^{2+}$ feedback. To achieve that, we exposed isolated mouse retinas to low $\sim 30 \mathrm{nM}\left[\mathrm{Ca}^{2+}\right]_{0}$ during ex vivo ERG recordings to study how mouse cone physiology is affected under low $\mathrm{Ca}^{2+}$ environment. Assuming that the extrusion of $\mathrm{Ca}^{2+}$ via the cone $\mathrm{Na}^{+} / \mathrm{Ca}^{2+}, \mathrm{K}^{+}$exchangers is linearly proportional to the intracellular $\mathrm{Ca}^{2+}$ concentration ${ }^{56}$, and that the conductance of $\mathrm{Ca}^{2+}$ is increased about $50 \%$ by low $\mathrm{Ca}^{2+}$ exposure in $\mathrm{GCAPs}^{-1-} \mathrm{Rv}^{-1-}$ cones (see Fig. $4 \mathrm{~A}$ below), it can be calculated that $\left[\mathrm{Ca}^{2+}\right]_{\text {in }}$ under these conditions will drop from $250 \mathrm{nM}$ in darkness in normal $\mathrm{Ca}^{2+57}$ to $\sim 1 \mathrm{nM}$. Thus, at steady state in low $\mathrm{Ca}^{2+}$ exposure, the level of $\left[\mathrm{Ca}^{2+}\right]_{\text {in }}$ in cones would be below its level even in very bright light, fully activating any $\mathrm{Ca}^{2+}$-mediated phototransduction feedbacks.

As has been shown previously for other photoreceptor types and/or species, the low $\mathrm{Ca}^{2+}$ exposure of retinas from control Gnat $1^{-1-}$ mice led to a significant but only transient increase of the maximal light response amplitude $\left(r_{\max }\right)$ in mouse cones (Fig. 3A; see also $\left.{ }^{10,39,58}\right)$. At steady state about 10 minutes after the switch to low $\mathrm{Ca}^{2+}$, the amplitude of $r_{\max }$ stabilized to approximately the same level as in normal $\mathrm{Ca}^{2+}$. However, comparison of dim flash responses in normal and low $\mathrm{Ca}^{2+}$ at steady state revealed a significant deceleration of response kinetics of cones caused by lowering $\mathrm{Ca}^{2+}$ (Fig. 3B), an effect similar to that observed previously in rod photoreceptors. Previous studies have suggested that the abnormally high cGMP in the photoreceptors exposed to low $\mathrm{Ca}^{2+}$ in darkness would not be well tolerated by the cells causing gradually declining response amplitudes ${ }^{10,58}$ and slowdown of their phototransduction ${ }^{44,53,59}$. 
A

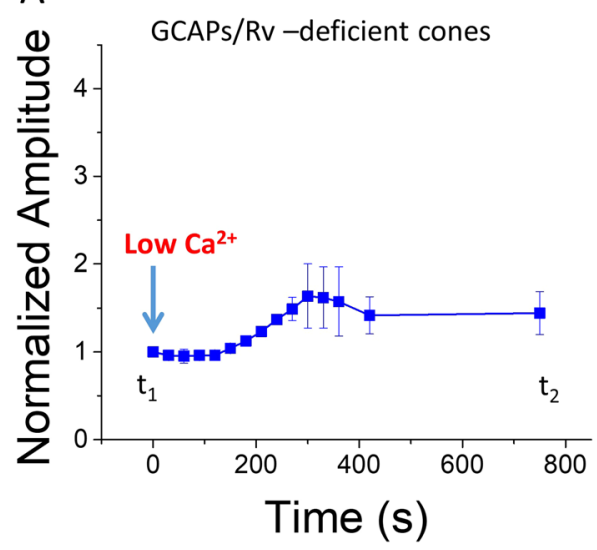

B

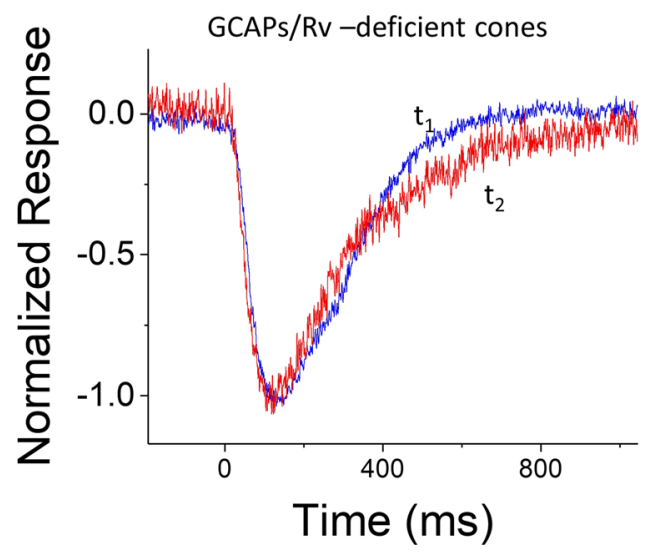

Figure 4. Low $\mathrm{Ca}^{2+}$ exposure causes moderate and stable increase of $\mathrm{r}_{\max }$ in GCAPs/recoverin-deficient cones. (A) Normalized maximal cone response amplitudes $\left(r_{\max }\right.$, mean $\pm \mathrm{SEM}, \mathrm{n}=3$ mice) to a saturating bright test flash plotted as a function of time after exposing the retina to low $\mathrm{Ca}^{2+}$ medium. Amplitudes have been normalized to $r_{\max }$ just before the low $\mathrm{Ca}^{2+}$ exposure. (B) Averaged normalized responses (mean, $\mathrm{n}=3 \mathrm{mice}$ ) of GCAPs/recoverin-deficient cones to a dim test flash producing a response with amplitude $<20 \%$ of $r_{\text {max }}$ just before the low $\mathrm{Ca}^{2+}$ exposure (black) and about $10 \mathrm{~min}$ after the switch to low $\mathrm{Ca}^{2+}$ solution (red).

In contrast to control cones, the cones of our $\mathrm{GCAPs}^{-1-} \mathrm{R} v^{-1-} \mathrm{Gnat1^{-1- }}$ mice lack the GCAP-mediated acceleration of cGMP synthesis at low $\mathrm{Ca}^{2+}$. Therefore, low $\mathrm{Ca}^{2+}$ exposure of these cones would not be expected to produce increase in their cGMP concentration. Consistent with this hypothesis, the large transient increase of the maximal cone response amplitudes observed after the switch to low $\mathrm{Ca}^{2+}$ in cones from control Gnat $1^{-1-}$ mice was absent in cones from GCAPs ${ }^{-l-} \mathrm{Rv}^{-l-} \mathrm{Gnat}^{-1-}$ mice (Fig. 4A). However, we still observed about 50\% increase of $r_{\max }$ by low $\mathrm{Ca}^{2+}$ exposure even in cones lacking GCAPs and recoverin (Fig. 4A), and these larger amplitudes remained stable for up to 30 minutes in most of the experiments. In striking contrast to the case in control cones, the kinetics of cone responses from $G C A P s^{-1-} R v^{-l-} G n a t 1^{-1-}$ mice were not decelerated by the low $\mathrm{Ca}^{2+}$ exposure (Fig. 4B). The stability of response amplitudes and the lack of phototransduction deceleration indicate that in the absence of GCAPs-mediated acceleration of cGMP synthesis low $\mathrm{Ca}^{2+}$ exposure does not induce any toxic effects. This allowed us to use this low $\mathrm{Ca}^{2+}$ method in $G C A P s^{-1-} \mathrm{Rv}^{-1-} \mathrm{Gnat1^{-l- }}$ mice to study the contribution of $\mathrm{Ca}^{2+}$-dependent and any possible $\mathrm{Ca}^{2+}$-independent mechanisms to the light adaptation of mouse cones in the absence of GCAPs- and recoverin-mediated regulation.

Cones lacking both GCAPs and recoverin can light adapt via both $\mathrm{Ca}^{2+}$-dependent and $\mathrm{Ca}^{2+}$-independent mechanisms. Finally, we evaluated the contribution of $\mathrm{Ca}^{2+}$-dependent and $\mathrm{Ca}^{2+}$-independent mechanisms of light adaptation in cones already devoid of their two known feedback mechanisms, via GCAPs and recoverin. To do that, we compared the light adaptation of GCAPs ${ }^{-1-} \mathrm{Rv}^{-1-} \mathrm{Gnat1}^{-{ }^{--}}$ mouse cones in normal $\mathrm{Ca}^{2+}$, where a potential dynamic light-induced $\mathrm{Ca}^{2+}$-dependent mechanism would be functional, and in low $\mathrm{Ca}^{2+}$, where any residual $\mathrm{Ca}^{2+}$ feedback would be driven to a fully light-adapted state. Exposure of cones lacking GCAPs and recoverin to a step of background light in normal $\mathrm{Ca}^{2+}$ produced an initial hyperpolarization, followed by partial recovery indicative of adaptation of the cone phototransduction cascade (Fig. 5A, blue). As shown in Fig. 2C, the decline in their sensitivity in backgrounds of increasing intensity was steeper than in control cones (i.e. $n$ increased upon deletion of GCAPs and Rv, Table 1), but still well above what would be expected in the lack of any adaptation (Fig. $5 \mathrm{~B}$ blue). These results suggest the existence of a feedback mechanism contributing to mouse cone light adaptation even in the absence of the known GCAPs- and recoverin-mediated pathways.

When GCAPs/recoverin-deficient cones were exposed to a step of light in low $\mathrm{Ca}^{2+}$, the rapid partial recovery in their response was no longer observable (Fig. 5A, red). In addition, the sensitivity of these cones in low $\mathrm{Ca}^{2+}$ started to decline at somewhat brighter background light intensities $(I)$ than in normal $\mathrm{Ca}^{2+}$ (i.e. $\mathrm{I}_{0}$ increased in low $\mathrm{Ca}^{2+}$, see Table 1). However, the subsequent decline was steeper (i.e. the steepness parameter $\mathrm{n}$ was larger in low $\mathrm{Ca}^{2+}$, see Table 1) so that the sensitivities under normal and low $\mathrm{Ca}^{2+}$ appeared to converge at brighter background light intensities (Fig. 5B, blue and red squares and solid lines). To quantitatively confirm convergence of the sensitivity in normal and low $\mathrm{Ca}^{2+}$, we performed statistical comparison of the normalized sensitivity data at five different background light intensities ranging from $\sim 6,000$ to 400,000 photons $\mu \mathrm{m}^{-2} \mathrm{~s}^{-1}$ using paired Student $\mathrm{t}$-test. The analysis from six $\mathrm{GCAPs}^{-1-} \mathrm{Rv}^{-1-} \mathrm{Gnat1}^{-/-}$mice demonstrated that the p-value, indicating significant difference, gradually increased from 0.01 to $0.01,0.03$, and 0.04 for the four dimmest backgrounds, and finally reached 0.13 , indicating no significant difference, for the brightest background. To evaluate whether GCAPs/ recoverin-deficient cones in low $\mathrm{Ca}^{2+}$ undergo any light adaptation, we calculated the predicted drop of sensitivity as a function of $I$ under low $\mathrm{Ca}^{2+}$ (Fig. 5B, dashed red and green lines). Although partially suppressed by the pharmacological reduction in $\mathrm{Ca}^{2+}$, these cones appeared to have a wider dynamic range and performed better than expected by the theoretical "no adaptation" model. To confirm the presence of light adaptation under low 
A

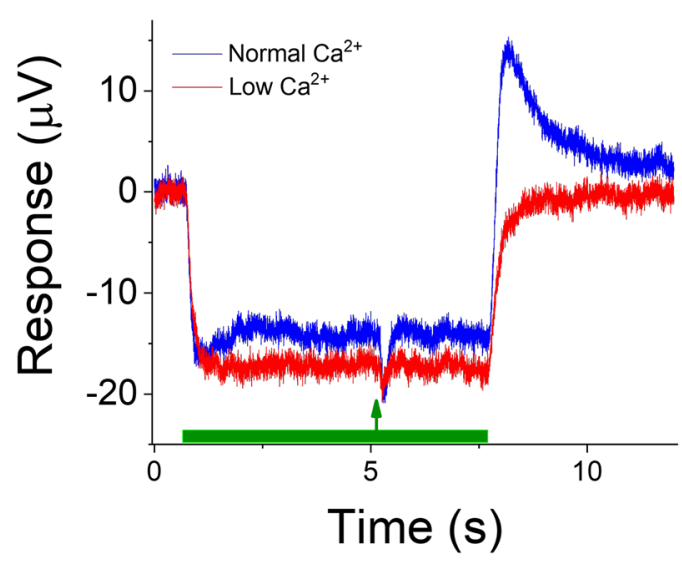

B

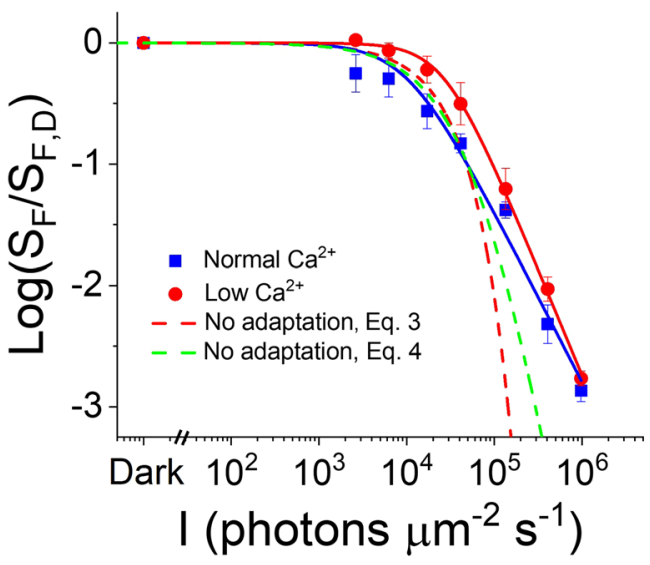

Figure 5. $\mathrm{Ca}^{2+}$-dependent and $\mathrm{Ca}^{2+}$-independent light adaptation mechanisms contribute to the light adaptation capacity of cones lacking both GCAPs and recoverin. (A) A response to a step of light (I=17,100 photons $\mu \mathrm{m}^{-2} \mathrm{~s}^{-1}$ ) superimposed with a test flash (arrow) recorded from GCAPs/recoverin-deficient cones in normal (blue) and low (red) $\mathrm{Ca}^{2+}$ (same retina). The test flash strength was 1,600 and 570 photons $\mu \mathrm{m}^{-2}$ in normal and low $\mathrm{Ca}^{2+}$, respectively. (B) Sensitivity of cones $\left(\mathrm{S}_{\mathrm{F}}\right)$ normalized to the sensitivity in darkness $\left(\mathrm{S}_{\mathrm{F}, \mathrm{D}}\right)$ plotted as function of background light intensity (I) for GCAPs/recoverin-deficient cones in normal (blue squares) and low (red squares) $\mathrm{Ca}^{2+}$. Smooth lines plot Eq. (2) with $\mathrm{I}_{0}=10,200$ photons $\mu \mathrm{m}^{-2} \mathrm{~s}^{-1}$ and $\mathrm{n}=1.4 \mathrm{in}$ normal $\mathrm{Ca}^{2+}$ (blue) and with $\mathrm{I}_{0}=27,000$ photons $\mu \mathrm{m}^{-2} \mathrm{~s}^{-1}$ and $\mathrm{n}=1.7$ in low $\mathrm{Ca}^{2+}$ (red). The dashed red and green traces plot Eqs (3) and (4), respectively, with parameter values calculated from dark-adapted responses of these cones in low $\mathrm{Ca}^{2+}$. Sensitivity data (mean $\pm \mathrm{SEM}$ ) in (B) is from $3 \mathrm{GCAPs}^{-1-} \mathrm{Rv}^{-1-} \mathrm{Gnat}^{-1-}$ mice for which we used identical background light intensities. The theoretical traces plot the mean values for the same 3 $\mathrm{GCAPs}^{-1-} \mathrm{Rv}^{-1-} \mathrm{Gnat1}^{-1-}$ mice. For comprehensive statistical analysis, see Table 1 and text.

$\mathrm{Ca}^{2+}$, we compared measured sensitivities and those calculated by Eq. 4 from six GCAPs ${ }^{-1-} \mathrm{Rv}^{-1-} \mathrm{Gnat1}^{-1-}$ mice at five different background light intensities ranging from $\sim 6,000$ to 400,000 photons $\mu \mathrm{m}^{-2} \mathrm{~s}^{-1}$. The sensitivity calculated by the model was lower at each of the five backgrounds (paired Student t-test, $\mathrm{p}<0.05$ ). We also analyzed if background light shortened the time-to-peak of a dim flash response of a dark adapted DKO cone under low $\mathrm{Ca}^{2+}$ perfusion. The time-to-peak shortened $38 \pm 6 \%$ (mean \pm SEM) under background of $\sim 150,000$ photons $\mu \mathrm{m}^{-2} \mathrm{~s}^{-1}$ as compared to that in darkness, a difference found to be highly significant $(\mathrm{n}=6, \mathrm{p}<0.005$, paired Student t-test). Further increase of background light intensity did not cause a further acceleration of response kinetics. Although voltage-gated channels and capacitive currents can also shape the ERG signals ${ }^{60-62}$, the robust Weber adaptation observed in our experiments indicates that these findings are not affected by voltage-dependent or capacitive currents. We conclude that, in striking contrast to mouse rods, mammalian cones appear to have a unique mechanism for $\mathrm{Ca}^{2+}$-independent light adaptation.

\section{Discussion}

Light-induced decrease in the photoreceptor outer segment $\mathrm{Ca}^{2+}$ concentration is a signal that mediates several feedback mechanisms via $\mathrm{Ca}^{2+}$ sensor proteins GCAPs ${ }^{28,29,46}$, recoverin ${ }^{32,34,40}$ and calmodulin/CNG modulin ${ }^{35,37}$ to modulate cGMP synthesis, active visual pigment lifetime, and CNG channels conductance, respectively. Many studies have indicated that $\mathrm{Ca}^{2+}$ is both necessary and sufficient for the light adaptation of amphibian photoreceptors, i.e. without $\mathrm{Ca}^{2+}$ feedbacks the responses of dark-adapted photoreceptors to single photons would be summed linearly leading to a rapid exponential saturation of these photoreceptors at very dim background light levels ${ }^{26,27,54}$. Some studies have suggested that $\mathrm{Ca}^{2+}$-independent adaptation mechanism(s) could also contribute to the light adaptation of amphibian rods ${ }^{63-66}$. However, Nikonov et al. ${ }^{63}$ have argued that in salamander rods the acceleration of response shut-off caused by background light is due to a trivial $\mathrm{Ca}^{2+}$-independent acceleration of cGMP turnover following activation of PDE by light and does not require existence of any specific feedback pathway. Furthermore, even if this increase in the steady state cGMP hydrolysis rate is taken into account, a significant amount of light adaptation persists even in mouse rods lacking GCAPs- and recoverin-mediated feedbacks ${ }^{39}$. In amphibians, the contribution of $\mathrm{Ca}^{2+}$-dependent mechanisms to the light adaptation capacity of photoreceptors has been studied mainly by manipulating the ionic environment around photoreceptor outer segments to prevent the light-induced change in their $\mathrm{Ca}^{2+}$ concentration (" $\mathrm{Ca}^{2+}$ clamp" method ${ }^{26,27,38,52,54}$ ). On the other hand, the role of different molecular mechanisms to the light adaptation of mouse, Xenopus and zebrafish photoreceptors has been studied by combining genetic and physiology approaches ${ }^{2,67,68}$. However, mouse photoreceptors are small and fragile making it very challenging to perform physiological recordings from their rods or cones in isolation. Thus, $\mathrm{Ca}^{2+}$ clamp experiments have not been performed successfully from mouse rod or cone photoreceptors.

As an alternative approach, light-induced decrease in $\mathrm{Ca}^{2+}$ concentration could be mimicked by reducing the extracellular $\mathrm{Ca}^{2+}$ that would drive the intracellular $\mathrm{Ca}^{2+}$ concentration to a lower level. However, in contrast to the light-induced acceleration of flash response kinetics, an exposure of photoreceptors to a very low $\mathrm{Ca}^{2+}$ 
in darkness causes a significant deceleration of flash response kinetics ${ }^{44,53,54,59}$. In addition, after the initial large increase, the CNG channel current gradually decreases following exposure to low $\mathrm{Ca}^{2+10,39}$. A light-induced drop in $\mathrm{Ca}^{2+}$ also causes acceleration of cGMP hydrolysis so that cGMP concentration or CNG channel current do not exceed the values observed in dark-adapted photoreceptors. In contrast, exposure to low $\mathrm{Ca}^{2+}$ in darkness is expected to increase cGMP concentration due to the GCAP-mediated feedback on guanylyl cyclase activity. The hypothesis that high cGMP is causing the anomalous effects of low $\mathrm{Ca}^{2+}$ exposure in mouse rods (directly or indirectly) was tested recently by exposing rods lacking the GCAP-mediated feedback on cyclase to a very low (about $30 \mathrm{nM}$ ) $\left[\mathrm{Ca}^{2+}\right]^{39}$. In striking contrast to wild type rods, the flash responses of $\mathrm{GCAPs}^{-/-}$rods were accelerated by low $\mathrm{Ca}^{2+}$ exposure. Thus, low $\mathrm{Ca}^{2+}$ exposure in the absence of GCAPs-mediated increase of cGMP concentration in rods is a viable approach for dissecting the contribution of $\mathrm{Ca}^{2+}$-dependent and $\mathrm{Ca}^{2+}$-independent mechanisms of phototransduction and light adaptation. Here, we applied this approach to study light adaptation in mouse cones that lack $\mathrm{Ca}^{2+}$ feedbacks mediated by GCAPs and recoverin by comparing the light adaptation of $G C A P^{-1-} \mathrm{Rv}^{-1-}$ Gnat $1^{-1-}$ mouse cones between normal $(1.2 \mathrm{mM})$ and low $(\sim 30 \mathrm{nM})$ extracellular $\left[\mathrm{Ca}^{2+}\right]$. As in wild type rods, cones expressing GCAPs also showed a significant but only transient increase of their $r_{\max }$ after exposure to low $\mathrm{Ca}^{2+}$ (Fig. 3A). Furthermore, similarly to mouse rods, the kinetics of their flash responses slowed down (Fig. 3B). However, the value of $r_{\max }$ of GCAPs/recoverin-deficient cones increased only moderately and remained relatively stable during low $\mathrm{Ca}^{2+}$ exposure (Fig. 4A). Importantly, the kinetics of flash responses also did not slow down by low $\mathrm{Ca}^{2+}$ exposure in these cones (Fig. 4B).

The $\mathrm{Ca}^{2+}$ concentration in the outer segments of photoreceptors is maintained at about 10,000-fold lower level than outside the cells by active extrusion of $\mathrm{Ca}^{2+}$ via $\mathrm{Na}^{+} / \mathrm{Ca}^{2+}, \mathrm{K}^{+}$exchangers $\left(\mathrm{NCKX},{ }^{25,69-71}\right)$. Thus, it is expected that during our low $\mathrm{Ca}^{2+}$ treatment, outer segment $\mathrm{Ca}^{2+}$ would be below the $\sim 20 \mathrm{nM}$ attained in bright light ${ }^{57}$ and well below the operating range of the potential $\mathrm{Ca}^{2+}$ feedback mechanisms. For example, the affinity of $\mathrm{Ca}^{2+}$ to mouse GCAP1 is $\sim 130 \mathrm{nM}$ and to GCAP2 $\sim 50 \mathrm{nM}^{72}$. Consequently, at $\sim 10 \mathrm{nM}$ almost all of the GCAPs would be in a $\mathrm{Ca}^{2+}$-free form and any further reduction caused by light would not have any modulatory effect on light adaptation. Indeed, the converging sensitivity of cones between normal and low $\mathrm{Ca}^{2+}$ when background light intensity increases suggests that during our low $\mathrm{Ca}^{2+}$ exposure, the cones are at physiological fully light-adapted state with regards to their $\mathrm{Ca}^{2+}$ feedback mechanisms (Fig. 5B).

Cones are much less sensitive to light and can operate at significantly brighter ambient illumination levels as compared to rods. A recent review summarized nicely what is known about differences of the phototransduction proteins and their expression levels between rod and cone photoreceptors, and how much these differences could contribute to the sensitivity difference of mouse rods and cones ${ }^{1}$. Studies comparing fish and avian rods and cones have demonstrated several differences in the activity and expression levels of rod- and cone-specific phototransduction proteins that could potentially explain the physiological differences between rods and cones (for review, $\mathrm{see}^{73}$ ). Thus, the cone-specific kinase GRK7 (though not expressed in mouse photoreceptors) is more active and highly expressed as compared to rod GRK $1^{13}$. The active form of chicken cone visual pigment, Meta II, decays 50 times faster than rhodopsin ${ }^{15}$. Cone pigments are also less stable ${ }^{22,74}$ and noisier than rod pigment ${ }^{75,76}$. In addition, the enzyme RGS9 known to accelerate inactivation of active transducing-phosphodiesterase complex, the cGMP-synthesizing enzyme guanylyl cyclase, as well as arrestins are expressed at higher levels in carp cones than in rods ${ }^{14,16,17}$. Quantification of expression levels of phototransduction proteins in mouse cones is challenging due to their very small percentage in the mouse retina. Many studies have tried to assess the different properties of cone vs. rod isoforms of visual pigments, G proteins and PDE6 by expressing the cone isoforms in the rod photoreceptors ${ }^{21,77-81}$. These studies suggest that differences in the activity of rod and cone phototransduction enzymes may contribute to the difference in the sensitivity of mouse rods and cones but the molecular origin of the sensitivity difference between mammalian rods and cones remains poorly understood ${ }^{1}$. It is known that the amphibian outer segment $\mathrm{Ca}^{2+}$ concentration changes more rapidly and over wider range in cones than in rods ${ }^{82,83}$. This could translate into more efficient regulation of cone phototransduction sensitivity by background light via $\mathrm{Ca}^{2+}$ feedback mechanisms. However, the main $\mathrm{Ca}^{2+}$ feedback, mediated by GCAPs, contributes similarly to the regulation of sensitivity and light adaptation in mouse rods and cones ${ }^{46}$. Although recoverin appears to contribute slightly more to the regulation of cone than rod phototransduction, its role in the mouse phototransduction and light adaptation is rather small both in rods and cones and certainly cannot explain the large differences between these cells ${ }^{32,40}$. A recent study demonstrated that rods lacking both GCAPs and recoverin still can light adapt via some other $\mathrm{Ca}^{2+}$-dependent mechanism ${ }^{39}$. Here, we show the cones of these mice also have a $\mathrm{Ca}^{2+}$-dependent light adaptation component. However, overall this residual $\mathrm{Ca}^{2+}$ feedback in GCAPs/recoverin-deficient mouse photoreceptors is rather small and its magnitude is not larger in cones than in rods (Fig. $5 \mathrm{~B}$ and ${ }^{39}$ ). On the other hand, our results reveal a substantial $\mathrm{Ca}^{2+}$-independent light adaptation component in mouse cones that is not present in rods. This adaptation is apparent even when the upregulation of cGMP flux by the background light is taken into consideration (Fig. 5B). Thus, surprisingly it appears that the difference between the adaptation capacities of mammalian rod and cone photoreceptors may not be explained by $\mathrm{Ca}^{2+}$-dependent mechanism. Instead, our findings suggest that future efforts in understanding the functional differences between rods and cones should be focused on identifying $\mathrm{Ca}^{2+}$-independent molecular mechanism(s).

Our results demonstrated a robust $\mathrm{Ca}^{2+}$-dependent light adaptation mechanism even in the absence of GCAPs and recoverin in mouse cones (Fig. 5B). We observed about $50 \%$ increase of $r_{\text {max }}$ by low $\mathrm{Ca}^{2+}$ exposure in $\mathrm{GCAPs}^{-1-} \mathrm{Rv}^{-1-} \mathrm{Gnat1}^{-1-}$ cones, indicating that some $\mathrm{Ca}^{2+}$-dependent mechanism can potentiate the CNG channel current in these cones (Fig. 4A). On the other hand, lowering $\mathrm{Ca}^{2+}$ did not affect much the response kinetics (Fig. 4B). A very small effect of low $\mathrm{Ca}^{2+}$ exposure to response kinetics in GCAPs ${ }^{-1-} \mathrm{Rv}^{-1-}$ Gnat $1^{-1-}$ cones (and rods) suggest that the $\mathrm{Ca}^{2+}$ feedback is not modulating cGMP hydrolysis or synthesis rate (Fig. 4B). Another potential mechanism for the observed $\mathrm{Ca}^{2+}$ feedback is the modulation of CNG channels. This modulation may be via a recently discovered CNG modulin or its mammalian homolog Eml1 ${ }^{35,36}$. Future studies combining genetics and cone physiology will be able to test these hypotheses. 
Our results clearly demonstrate the robust function of a $\mathrm{Ca}^{2+}$-independent mechanism for light adaptation in mouse cones (Fig. 5B) that is not present in $\operatorname{rods}^{39}$. One trivial explanation for this residual light adaptation in cones is a simple light-induced acceleration of cGMP hydrolysis. The reduction in free cGMP will result in easier and faster subsequent change of the fractional cGMP concentration even without upregulating cGMP synthesis ${ }^{63}$. However, using a phototransduction model with all active feedbacks removed to estimate the drop of sensitivity ${ }^{45}$ reveals that a significant amount of light adaptation persists in GCAPs/recoverin-deficient cones even in low $\mathrm{Ca}^{2+}$ (Fig. 5B, dashed green trace). Comparing the flash responses in darkness and under various backgrounds in their cones under low $\mathrm{Ca}^{2+}$ exposure shows that background light can progressively accelerate light response termination (see Results). Thus, it is possible that the novel $\mathrm{Ca}^{2+}$-independent mechanism identified here accelerates cGMP synthesis rate. In principle, this could be related to a recently suggested bicarbonate-dependent modulation of guanylyl cyclase although it is not clear whether bicarbonate concentration can be modulated in background light-dependent manner ${ }^{84}$. Another possible mechanism for the $\mathrm{Ca}^{2+}$-independent adaptation could be a recently discovered pathway acting via IGF-1 and all-trans-retinol to regulate the rod CNG channels ${ }^{66,85}$. This mechanism causes potentiation (increase of light sensitivity) of rod response amplitudes in background light. Whether it can contribute to the light adaptation in mouse cones and explain the $\mathrm{Ca}^{2+}$-independent light adaptation observed here will be an interesting subject for future studies.

\section{Data Availability Statement}

The datasets generated and analysed during the current study are available from the corresponding author on reasonable request.

\section{References}

1. Ingram, N. T., Sampath, A. P. \& Fain, G. L. Why are rods more sensitive than cones? J Physiol, https://doi.org/10.1113/JP272556 (2016).

2. Kefalov, V. J. Rod and cone visual pigments and phototransduction through pharmacological, genetic, and physiological approaches. J Biol Chem 287, 1635-1641, https://doi.org/10.1074/jbc.R111.303008 (2012).

3. Fung, B. K., Hurley, J. B. \& Stryer, L. Flow of information in the light-triggered cyclic nucleotide cascade of vision. Proc Natl Acad Sci USA 78, 152-156 (1981).

4. Kuhn, H. Light- and GTP-regulated interaction of GTPase and other proteins with bovine photoreceptor membranes. Nature 283, 587-589 (1980).

5. Lerea, C. L., Somers, D. E., Hurley, J. B., Klock, I. B. \& Bunt-Milam, A. H. Identification of specific transducin alpha subunits in retinal rod and cone photoreceptors. Science 234, 77-80 (1986).

6. Baehr, W., Devlin, M. J. \& Applebury, M. L. Isolation and characterization of cGMP phosphodiesterase from bovine rod outer segments. J. Biol. Chem. 254, 11669-11677 (1979).

7. Li, T. S., Volpp, K. \& Applebury, M. L. Bovine cone photoreceptor cGMP phosphodiesterase structure deduced from a cDNA clone. Proc Natl Acad Sci USA 87, 293-297 (1990).

8. Fesenko, E. E., Kolesnikov, S. S. \& Lyubarsky, A. L. Induction by cyclic GMP of cationic conductance in plasma membrane of retinal rod outer segment. Nature 313, 310-313 (1985).

9. Hagins, W. A., Penn, R. D. \& Yoshikami, S. Dark current and photocurrent in retinal rods. Biophys. J. 10, 380-412, https://doi. org/10.1016/S0006-3495(70)86308-1 (1970).

10. Yau, K. W., McNaughton, P. A. \& Hodgkin, A. L. Effect of ions on the light-sensitive current in retinal rods. Nature 292, 502-505 (1981).

11. Pannbacker, R. G. Control of guanylate cyclase activity in the rod outer segment. Science 182, 1138-1140 (1973).

12. Kondo, H. \& Miller, W. H. Rod light adaptation may be mediated by acceleration of the phosphodiesterase-guanylate cyclase cycle. Proc Natl Acad Sci USA 85, 1322-1326 (1988).

13. Tachibanaki, S., Arinobu, D., Shimauchi-Matsukawa, Y., Tsushima, S. \& Kawamura, S. Highly effective phosphorylation by G protein-coupled receptor kinase 7 of light-activated visual pigment in cones. Proc Natl Acad Sci USA 102, 9329-9334, https://doi. org/10.1073/pnas.0501875102 (2005).

14. Tomizuka, J., Tachibanaki, S. \& Kawamura, S. Phosphorylation-independent suppression of light-activated visual pigment by arrestin in carp rods and cones. J. Biol. Chem. 290, 9399-9411, https://doi.org/10.1074/jbc.M114.634543 (2015).

15. Shichida, Y., Imai, H., Imamoto, Y., Fukada, Y. \& Yoshizawa, T. Is chicken green-sensitive cone visual pigment a rhodopsin-like pigment? A comparative study of the molecular properties between chicken green and rhodopsin. Biochemistry 33, 9040-9044 (1994).

16. Tachibanaki, S., Yonetsu, S., Fukaya, S., Koshitani, Y. \& Kawamura, S. Low activation and fast inactivation of transducin in carp cones. J. Biol. Chem. 287, 41186-41194, https://doi.org/10.1074/jbc.M112.403717 (2012).

17. Takemoto, N., Tachibanaki, S. \& Kawamura, S. High cGMP synthetic activity in carp cones. Proc Natl Acad Sci USA 106, 11788-11793, https://doi.org/10.1073/pnas.0812781106 (2009).

18. Cowan, C. W., Fariss, R. N., Sokal, I., Palczewski, K. \& Wensel, T. G. High expression levels in cones of RGS9, the predominant GTPase accelerating protein of rods. Proc Natl Acad Sci USA 95, 5351-5356 (1998).

19. Zhang, X., Wensel, T. G. \& Kraft, T. W. GTPase regulators and photoresponses in cones of the eastern chipmunk. J. Neurosci. 23, $1287-1297$ (2003).

20. Nikonov, S. S. et al. Mouse cones require an arrestin for normal inactivation of phototransduction. Neuron 59, 462-474, https://doi. org/10.1016/j.neuron.2008.06.011 (2008).

21. Majumder, A. et al. Exchange of Cone for Rod Phosphodiesterase 6 Catalytic Subunits in Rod Photoreceptors Mimics in Part Features of Light Adaptation. J. Neurosci. 35, 9225-9235, https://doi.org/10.1523/JNEUROSCI.3563-14.2015 (2015).

22. Kefalov, V. J. et al. Breaking the covalent bond-a pigment property that contributes to desensitization in cones. Neuron 46, 879-890, https://doi.org/10.1016/j.neuron.2005.05.009 (2005).

23. Nikonov, S. S., Kholodenko, R., Lem, J. \& Pugh, E. N. Jr. Physiological features of the S- and M-cone photoreceptors of wild-type mice from single-cell recordings. J Gen Physiol 127, 359-374, https://doi.org/10.1085/jgp.200609490 (2006).

24. Fain, G. L., Matthews, H. R., Cornwall, M. C. \& Koutalos, Y. Adaptation in vertebrate photoreceptors. Physiol. Rev. 81, 117-151 (2001).

25. Yau, K. W. \& Nakatani, K. Electrogenic Na-Ca exchange in retinal rod outer segment. Nature 311, 661-663 (1984).

26. Nakatani, K. \& Yau, K. W. Calcium and light adaptation in retinal rods and cones. Nature 334, 69-71, https://doi. org/10.1038/334069a0 (1988).

27. Matthews, H. R., Murphy, R. L., Fain, G. L. \& Lamb, T. D. Photoreceptor light adaptation is mediated by cytoplasmic calcium concentration. Nature 334, 67-69, https://doi.org/10.1038/334067a0 (1988). 
28. Mendez, A. et al. Role of guanylate cyclase-activating proteins (GCAPs) in setting the flash sensitivity of rod photoreceptors. Proc Natl Acad Sci USA 98, 9948-9953, https://doi.org/10.1073/pnas.171308998 (2001).

29. Koch, K. W. \& Stryer, L. Highly cooperative feedback control of retinal rod guanylate cyclase by calcium ions. Nature 334, 64-66, https://doi.org/10.1038/334064a0 (1988).

30. Matthews, H. R., Cornwall, M. C. \& Crouch, R. K. Prolongation of actions of Ca2+ early in phototransduction by 9-demethylretinal. J. Gen. Physiol. 118, 377-390 (2001).

31. Chen, C. K., Woodruff, M. L., Chen, F. S., Chen, D. \& Fain, G. L. Background light produces a recoverin-dependent modulation of activated-rhodopsin lifetime in mouse rods. J Neurosci 30, 1213-1220, https://doi.org/10.1523/JNEUROSCI.4353-09.2010 (2010).

32. Sakurai, K., Chen, J., Khani, S. C. \& Kefalov, V. J. Regulation of mammalian cone phototransduction by recoverin and rhodopsin kinase. J Biol Chem 290, 9239-9250, https://doi.org/10.1074/jbc.M115.639591 (2015).

33. Dizhoor, A. M. et al. Recoverin: a calcium sensitive activator of retinal rod guanylate cyclase. Science 251, 915-918 (1991).

34. Gorodovikova, E. N., Gimelbrant, A. A., Senin, I. I. \& Philippov, P. P. Recoverin mediates the calcium effect upon rhodopsin phosphorylation and cGMP hydrolysis in bovine retina rod cells. FEBS Lett. 349, 187-190 (1994).

35. Rebrik, T. I., Botchkina, I., Arshavsky, V. Y., Craft, C. M. \& Korenbrot, J. I. CNG-modulin: a novel Ca-dependent modulator of ligand sensitivity in cone photoreceptor cGMP-gated ion channels. J. Neurosci. 32, 3142-3153, https://doi.org/10.1523/ JNEUROSCI.5518-11.2012 (2012).

36. Korenbrot, J. I., Mehta, M., Tserentsoodol, N., Postlethwait, J. H. \& Rebrik, T. I. EML1 (CNG-modulin) controls light sensitivity in darkness and under continuous illumination in zebrafish retinal cone photoreceptors. J. Neurosci. 33, 17763-17776, https://doi. org/10.1523/JNEUROSCI.2659-13.2013 (2013).

37. Hsu, Y. T. \& Molday, R. S. Modulation of the cGMP-gated channel of rod photoreceptor cells by calmodulin. Nature 361, 76-79, https://doi.org/10.1038/361076a0 (1993).

38. Fain, G. L., Lamb, T. D., Matthews, H. R. \& Murphy, R. L. Cytoplasmic calcium as the messenger for light adaptation in salamander rods. J Physiol 416, 215-243 (1989).

39. Vinberg, F., Turunen, T. T., Heikkinen, H., Pitkanen, M. \& Koskelainen, A. A novel Ca2+-feedback mechanism extends the operating range of mammalian rods to brighter light. J Gen Physiol 146, 307-321, https://doi.org/10.1085/jgp.201511412 (2015).

40. Makino, C. L. et al. Recoverin regulates light-dependent phosphodiesterase activity in retinal rods. J Gen Physiol 123, 729-741, https://doi.org/10.1085/jgp.200308994 (2004).

41. Calvert, P. D. et al. Phototransduction in transgenic mice after targeted deletion of the rod transducin alpha -subunit. Proc Natl Acad Sci USA 97, 13913-13918, https://doi.org/10.1073/pnas.250478897 (2000).

42. Mattapallil, M. J. et al. The Rd8 mutation of the Crb1 gene is present in vendor lines of C57BL/6N mice and embryonic stem cells, and confounds ocular induced mutant phenotypes. Invest Ophthalmol Vis Sci 53, 2921-2927, https://doi.org/10.1167/iovs.12-9662 (2012).

43. Vinberg, F., Wang, T., Molday, R. S., Chen, J. \& Kefalov, V. J. A new mouse model for stationary night blindness with mutant Slc24a1 explains the pathophysiology of the associated human disease. Hum. Mol. Gene., https://doi.org/10.1093/hmg/ddv319 (2015).

44. Vinberg, F. \& Koskelainen, A. Calcium sets the physiological value of the dominant time constant of saturated mouse rod photoresponse recovery. PLoS One 5, e13025, https://doi.org/10.1371/journal.pone.0013025 (2010).

45. Chen, J. et al. Channel modulation and the mechanism of light adaptation in mouse rods. J Neurosci 30, 16232-16240, https://doi. org/10.1523/JNEUROSCI.2868-10.2010 (2010).

46. Sakurai, K., Chen, J. \& Kefalov, V. J. Role of guanylyl cyclase modulation in mouse cone phototransduction. J. Neurosci. 31, 7991-8000, https://doi.org/10.1523/JNEUROSCI.6650-10.2011 (2011).

47. Makino, C. L. et al. Enzymatic relay mechanism stimulates cyclic GMP synthesis in rod photoresponse: biochemical and physiological study in guanylyl cyclase activating protein 1 knockout mice. PLoS One 7, e47637, https://doi.org/10.1371/journal. pone.0047637 (2012).

48. Chen, C. K. et al. Modulation of mouse rod response decay by rhodopsin kinase and recoverin. J. Neurosci. 32, 15998-16006, https:// doi.org/10.1523/JNEUROSCI.1639-12.2012 (2012).

49. Chen, C. K., Woodruff, M. L. \& Fain, G. L. Rhodopsin kinase and recoverin modulate phosphodiesterase during mouse photoreceptor light adaptation. J Gen Physiol 145, 213-224, https://doi.org/10.1085/jgp.201411273 (2015).

50. Koutalos, Y., Nakatani, K., Tamura, T. \& Yau, K. W. Characterization of guanylate cyclase activity in single retinal rod outer segments. J. Gen. Physiol. 106, 863-890 (1995).

51. Koutalos, Y., Nakatani, K. \& Yau, K. W. The cGMP-phosphodiesterase and its contribution to sensitivity regulation in retinal rods. J. Gen. Physiol. 106, 891-921 (1995).

52. Lyubarsky, A., Nikonov, S. \& Pugh, E. N. Jr. The kinetics of inactivation of the rod phototransduction cascade with constant Ca2+i. J. Gen. Physiol. 107, 19-34 (1996).

53. Hodgkin, A. L., McNaughton, P. A., Nunn, B. J. \& Yau, K. W. Effect of ions on retinal rods from Bufo marinus. J Physiol 350, 649-680 (1984).

54. Matthews, H. R. Effects of lowered cytoplasmic calcium concentration and light on the responses of salamander rod photoreceptors. J Physiol 484(Pt 2), 267-286 (1995).

55. Sather, W. A. \& Detwiler, P. B. Intracellular biochemical manipulation of phototransduction in detached rod outer segments. Proc Natl Acad Sci USA 84, 9290-9294 (1987).

56. Lagnado, L., Cervetto, L. \& McNaughton, P. A. Ion transport by the Na-Ca exchange in Isolated rod outer segments. Proc Natl Acad Sci USA 85, 4548-4552 (1988).

57. Woodruff, M. L. et al. Measurement of cytoplasmic calcium concentration in the rods of wild-type and transducin knock-out mice. J Physiol 542, 843-854 (2002).

58. Winkler, B. S. The electroretinogram of the isolated rat retina. Vision Res. 12, 1183-1198 (1972).

59. Bastian, B. L. \& Fain, G. L. The effects of low calcium and background light on the sensitivity of toad rods. J Physiol 330, 307-329 (1982).

60. Vinberg, F. J., Strandman, S. \& Koskelainen, A. Origin of the fast negative ERG component from isolated aspartate-treated mouse retina. J Vis 9(9), 1-17, https://doi.org/10.1167/9.12.9 (2009).

61. Robson, J. G. \& Frishman, L. J. The rod-driven a-wave of the dark-adapted mammalian electroretinogram. Prog Retin Eye Res 39, 1-22, https://doi.org/10.1016/j.preteyeres.2013.12.003 (2014)

62. Pahlberg, J. et al. Voltage-sensitive conductances increase the sensitivity of rod photoresponses following pigment bleaching. $J$ Physiol 595, 3459-3469, https://doi.org/10.1113/JP273398 (2017).

63. Nikonov, S., Lamb, T. D. \& Pugh, E. N. Jr. The role of steady phosphodiesterase activity in the kinetics and sensitivity of the lightadapted salamander rod photoresponse. J Gen Physiol 116, 795-824 (2000).

64. Nicol, G. D. \& Bownds, M. D. Calcium regulates some, but not all, aspects of light adaptation in rod photoreceptors. J. Gen. Physiol. 94, 233-259 (1989).

65. Kawamura, S. \& Murakami, M. Regulation of cGMP levels by guanylate cyclase in truncated frog rod outer segments. J. Gen. Physiol. 94, 649-668 (1989).

66. McKeown, A. S., Pitale, P. M. \& Kraft, T. W. Signalling beyond photon absorption: extracellular retinoids and growth factors modulate rod photoreceptor sensitivity. J Physiol 594, 1841-1854, https://doi.org/10.1113/JP271650 (2016). 
67. Fadool, J. M. \& Dowling, J. E. Zebrafish: a model system for the study of eye genetics. Prog Retin Eye Res 27, 89-110, https://doi. org/10.1016/j.preteyeres.2007.08.002 (2008).

68. Fu, Y. \& Yau, K. W. Phototransduction in mouse rods and cones. Pflugers Arch 454, 805-819, https://doi.org/10.1007/s00424-0060194-y (2007).

69. Reilander, H. et al. Primary structure and functional expression of the $\mathrm{Na} / \mathrm{Ca}, \mathrm{K}$-exchanger from bovine rod photoreceptors. EMBO J. 11, 1689-1695 (1992).

70. Prinsen, C. F., Szerencsei, R. T. \& Schnetkamp, P. P. Molecular cloning and functional expression of the potassium-dependent sodium-calcium exchanger from human and chicken retinal cone photoreceptors. J. Neurosci. 20, 1424-1434 (2000).

71. Vinberg, F. et al. The $\mathrm{Na}+/ \mathrm{Ca} 2+, \mathrm{K}+$ exchanger NCKX4 is required for efficient cone-mediated vision. Elife 6, https://doi. org/10.7554/eLife.24550 (2017).

72. Peshenko, I. V. et al. Enzymatic properties and regulation of the native isozymes of retinal membrane guanylyl cyclase (RetGC) from mouse photoreceptors. Biochemistry 50, 5590-5600, https://doi.org/10.1021/bi200491b (2011).

73. Kawamura, S. \& Tachibanaki, S. Rod and cone photoreceptors: molecular basis of the difference in their physiology. Comp Biochem Physiol A Mol Integr Physiol 150, 369-377, https://doi.org/10.1016/j.cbpa.2008.04.600 (2008).

74. Wald, G., Brown, P. K. \& Smith, P. H. Iodopsin. J Gen Physiol 38, 623-681 (1955).

75. Rieke, F. \& Baylor, D. A. Origin and functional impact of dark noise in retinal cones. Neuron 26, 181-186 (2000).

76. Kefalov, V., Fu, Y., Marsh-Armstrong, N. \& Yau, K. W. Role of visual pigment properties in rod and cone phototransduction. Nature 425, 526-531, https://doi.org/10.1038/nature01992 (2003).

77. Sakurai, K. et al. Physiological properties of rod photoreceptor cells in green-sensitive cone pigment knock-in mice. J. Gen. Physiol. 130, 21-40, https://doi.org/10.1085/jgp.200609729 (2007).

78. Shi, G., Yau, K. W., Chen, J. \& Kefalov, V. J. Signaling properties of a short-wave cone visual pigment and its role in phototransduction. J Neurosci 27, 10084-10093, https://doi.org/10.1523/JNEUROSCI.2211-07.2007 (2007).

79. Fu, Y., Kefalov, V., Luo, D. G., Xue, T. \& Yau, K. W. Quantal noise from human red cone pigment. Nat Neurosci 11, 565-571, https:// doi.org/10.1038/nn.2110 (2008)

80. Chen, C. K. et al. Replacing the rod with the cone transducin subunit decreases sensitivity and accelerates response decay. J Physiol 588, 3231-3241, https://doi.org/10.1113/jphysiol.2010.191221 (2010).

81. Mao, W. et al. Functional comparison of rod and cone Galpha(t) on the regulation of light sensitivity. J. Biol. Chem. 288, 5257-5267, https://doi.org/10.1074/jbc.M112.430058 (2013).

82. Sampath, A. P., Matthews, H. R., Cornwall, M. C., Bandarchi, J. \& Fain, G. L. Light-dependent changes in outer segment freeCa2+ concentration in salamander cone photoreceptors. J Gen Physiol 113, 267-277 (1999).

83. Sampath, A. P., Matthews, H. R., Cornwall, M. C. \& Fain, G. L. Bleached pigment produces a maintained decrease in outer segment Ca2+ in salamander rods. J Gen Physiol 111, 53-64 (1998).

84. Duda, T., Wen, X. H., Isayama, T., Sharma, R. K. \& Makino, C. L. Bicarbonate Modulates Photoreceptor Guanylate Cyclase (ROSGC) Catalytic Activity. J. Biol. Chem. 290, 11052-11060, https://doi.org/10.1074/jbc.M115.650408 (2015).

85. McKeown, A. S., Kraft, T. W. \& Loop, M. S. Increased visual sensitivity following periods of dim illumination. Invest Ophthalmol Vis Sci 56, 1864-1871, https://doi.org/10.1167/iovs.14-15958 (2015).

\section{Acknowledgements}

This work was supported by National Institutes of Health grants EY026651 (F.V.), EY027387 and EY019312 (V.J.K.), and EY02687 (Washington University, Department Ophthalmology), Research to Prevent Blindness, and the Ella \& Georg Ehrnrooth Foundation (F.V.). We thank Jeannie Chen from the University of Southern California for the GCAPs ${ }^{-1-}$ and $\mathrm{Rv}^{-1-}$ mice, and Janis Lem from Tufts University for the Gnat $1^{-1-}$ animals.

\section{Author Contributions}

F.V. and V.J.K contributed to study conception, design and data interpretation. F.V. and V.J.K wrote the manuscript. F.V. conducted the experiments and analyzed the data.

\section{Additional Information}

Competing Interests: The authors declare no competing interests.

Publisher's note: Springer Nature remains neutral with regard to jurisdictional claims in published maps and institutional affiliations.

(c) (i) Open Access This article is licensed under a Creative Commons Attribution 4.0 International License, which permits use, sharing, adaptation, distribution and reproduction in any medium or format, as long as you give appropriate credit to the original author(s) and the source, provide a link to the Creative Commons license, and indicate if changes were made. The images or other third party material in this article are included in the article's Creative Commons license, unless indicated otherwise in a credit line to the material. If material is not included in the article's Creative Commons license and your intended use is not permitted by statutory regulation or exceeds the permitted use, you will need to obtain permission directly from the copyright holder. To view a copy of this license, visit http://creativecommons.org/licenses/by/4.0/.

(C) The Author(s) 2018 